\title{
PENDUGAAN POPULASI BEKANTAN (Nasalis larvatus) DI TAMAN WISATA ALAM TANJUNG BELIMBING KECAMATAN PALOH KABUPATEN SAMBAS
}

\author{
(Estimation Population Of Proboscis Monkey (Nasalis larvatus) In Taman Wisata Alam \\ Tanjung Belimbing Subdistric Of Paloh Sambas Regency)
}

\author{
Selpa, Slamet Rifanjani, Muflihati \\ Fakultas Kehutanan Universitas Tanjungpura Jalan Imam Bonjol, Pontianak 78124 \\ E-mail: selpatamrin@gmail.com
}

\begin{abstract}
Proboscis monkey (Nasalis larvatus) is an endemic animal of Borneo including protected primate species as an endangered species status. This species listed as an endangered species caused by large population decline and habitat demage continues to threaten the proboscis population. This research was conducted in Taman Wisata Alam Tanjung Belimbing (TWATB) is a nature conservation area that supports the conservation of proboscis monkey. The purpose of this research is to collect the amount of proboscis monkey populations, so as to provide an overview of conservation efforts that must be carried out. The method was used the River Survey method. The result of Proboscis research based on the age level was found consisted average of 5 adult male individuals, 6 adult female individuals, 7 adolescent individuals and 5 childs. Estimation of the population is calculated using the King's Method. Estimated individuals population is 12 individuals with a density of 25.5 individuals $/ \mathrm{km}^{2}$.
\end{abstract}

Keywords: Proboscis monkey, Population, Tanjung Belimbing, Paloh.

\section{PENDAHULUAN}

Taman Wisata Alam merupakan kawasan pelestarian alam yang dimanfaatkan sebagai pariwisata dan rekreasi alam (UU RI, 1990). Taman Wisata Alam Tanjung Belimbing (TWATB) merupakan kawasan yang dilindungi berdasarkan peraturan Daerah Tingkat 1 Kalimantan Barat dan disahkan berdasarkan Surat Keputusan Menteri Dalam Negeri Nomor 143 Tahun 1995. TWATB memiliki dua ekosistem hutan, yaitu ekosistem hutan pantai dan hutan mangrove. Hutan mangrove di TWATB memiliki keanekaragaman jenis primata seperti Lutung (Presbitys sp), Monyet ekor panjang (Macaca fascicularis) dan
Bekantan (Nasalis larvatus) (BKSDA, 2014).

Bekantan merupakan salahsatu primata endemik Kalimantan yang termasuk kedalam subfamily Colobinae, umumnya berhabitat di hutan lahan basah yang berada didalam maupun di luar kawasan konservasi (Soenjoto, et al., 2005). Habitat bekantan berupa hutan riparian sepanjang sungai, hutan rawa gambut dan hutan dataran kering di hulu sungai. Penyebaran populasi bekantan di Kalimantan meliputi Kalimantan Timur, Kalimantan Selatan, Kalimantan Tengah, Kalimantan Utara, dan Kalimantan Barat.

Keberadaan bekantan di daerah hulu Sungai Kapuas di Kalimantan 
Barat mengalami penurunan, tetapi bekantan masih dapat ditemui dibeberapa bagian pesisir (Kartono et al., 2008), salah satunya adalah di Paloh Kabupaten Sambas. Hasil evaluasi bekantan di hutan mangrove selama 10 tahun terjadi penurunan populasi bekantan pertahun sebanyak 3\% (Bismark, 2002). Pada tahun 1994 populasi bekantan di Kalimantan diperkirakan sejumlah 114.000 individu (Bismark, 2009). Laporan simposium PHVA (Population and Habitat Viability Analysis) bekantan tahun 2004, populasi bekantan diduga tinggal 25.000 individu, dan yang berada di kawasan konservasi 5.000 individu (Manangsang et al., 2005).

Secara nasional bekantan tergolong kedalam satwa dilindungi berdasarkan Peraturan Menteri Lingkungan Hidup dan Kehutanan Republik Indonesia Nomor P.106 Tahun 2018 tentang Jenis Tumbuhan dan Satwa yang dilindungi. Secara Internasional status konservasi bekantan termasuk kedalam endangered species (IUCN, 2019) dan Appendix I CITES untuk status perdagangan. Sebagai spesies primata dengan prioritas tinggi (Permenhut, 2008) dan untuk meningkatkan usaha konservasi Bekantan di habitatnya, pemerintah telah menyusun Strategi dan Rencana Aksi Konservasi (SRAK) Bekantan. Salah satu ruang lingkup SRAK 20132022 adalah pengelolaan populasi yang bertujuan agar populasi bekantan dapat meningkat. Penelitian ini bertujuan untuk mendata jumlah populasi bekantan di TWATB, Kecamatan Paloh Kabupaten Sambas.

\section{METODE PENELITIAN}

Penelitian ini dilaksanakan Taman Wisata Alam Tanjung Belimbing (TWATB), Kecamatan Paloh, Kabupaten Sambas pada bulan JanuariFebruari 2019. Alat untuk penelitian ini ada peta lokasi, kamera, teropong binokuler, GPS, counter, perahu, Objek penelitian adalah bekantan (Nasalis larvatus). Metode penelitian menggunakan metode River Survey (Sha JCM, et al., 2008). Metode ini merupakan metode survei dengan menggunakan perahu dan menelusuri sungai sepanjang jalur penelitian.

Jalur pengamatan mengikuti alur sungai sepanjang hutan mangrove, dibuat sebanyak 9 jalur dengan panjang jalur masing-masing 1000 meter dengan titik jalur pertama diletakkan dibagian hulu sungai. Pengamatan dilakukan sebanyak 3 kali ulangan dengan waktu pengamatan mulai dari pukul 05.30 sampai 18.30 WIB. Data yang dikumpulkan dimasukkan kedalam tabel kemudian dilakukan perhitungan jumlah individu, dan kelompok populasi bekantan menggunakan Metode King (Iskandar et al., 2017) :

$D=\sum X_{i}$ /2.L.w

Keterangan

D : Kepadatan (Individu/ $/ \mathrm{km}^{2}$ )

$\sum \boldsymbol{X}_{\boldsymbol{i}}$ : Jumlah individu suatu jenis (individu) yang dijumpai pada kontak ke- $i$

$\boldsymbol{L} \quad$ : Panjang transek jalur pengamatan $(\mathrm{km})$ 
$\boldsymbol{w} \quad$ : Lebar kiri atau kanan jalur pengamatan $(\mathrm{m})$

$P=D x L_{R E P}$

Keterangan

$\boldsymbol{P} \quad$ : Estimasi populasi (Individu)
D : $\quad$ Kepadatan populasi (individu $/ \mathrm{km}^{2}$ )

$\boldsymbol{L}_{\boldsymbol{R E P}}$ : Luas habitat representatif $\left(\mathrm{km}^{2}\right)$

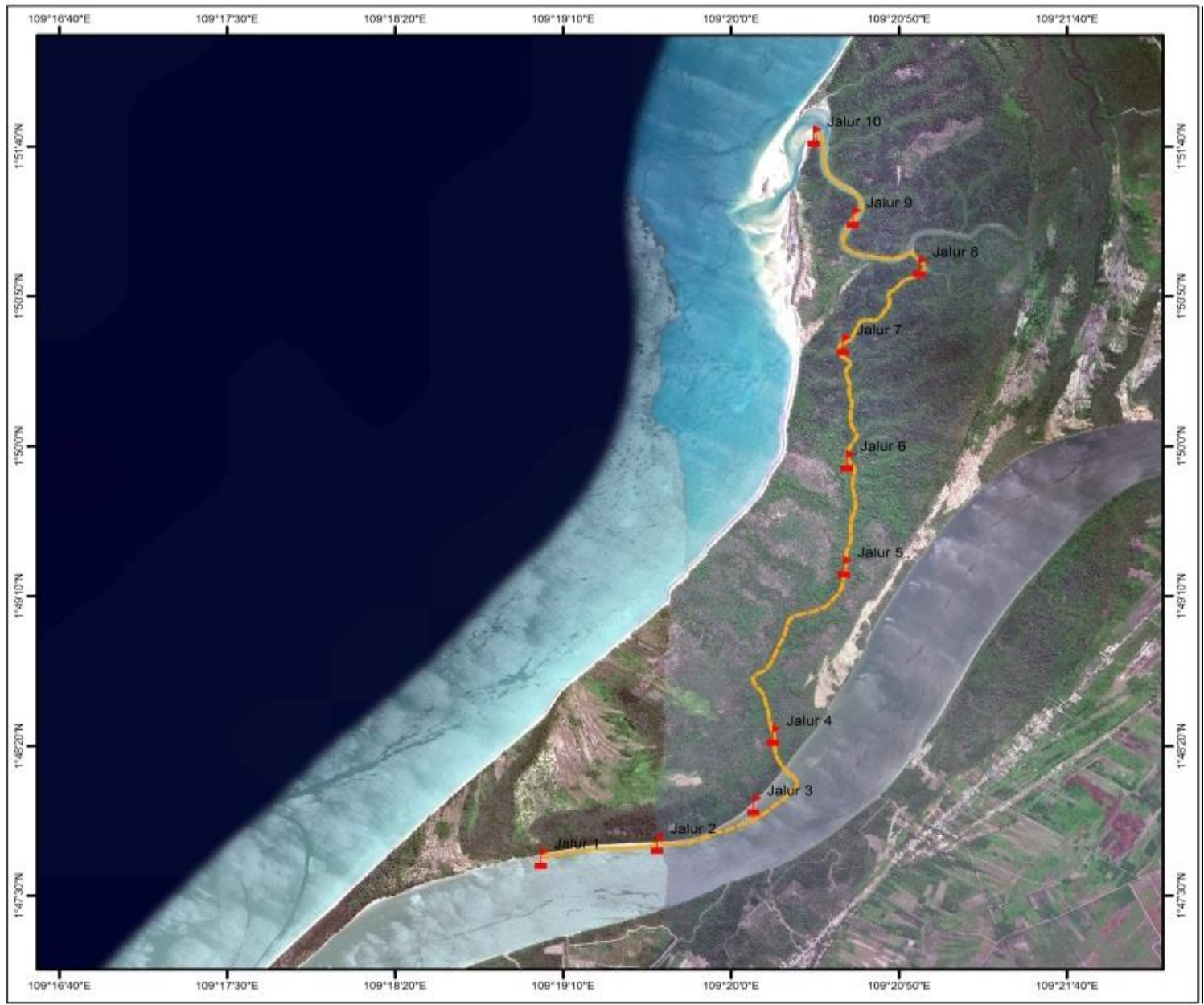

Gambar 1. Peta Citra Lokasi Pengamatan Bekantan di TWATB, Paloh. (Image Map of Bekantan Observation Location in TWATB, Paloh)

\section{HASIL DAN PEMBAHASAN}

\section{Perjumpaan Bekantan}

Pengamatan bekantan di Taman Wisata Alam Tanjung Belimbing (TWATB) dilakukan sepanjang Sungai Sebubus Paloh sepanjang $9 \mathrm{~km}$.

Pengamatan bekantan dilakukan pada pagi dan sore hari. Perjumpaan bekantan hanya ditemukan pada sore hari karena pada saat itu air sungai dalam keadaan surut dan bekantan dijumpai sedang melakukan aktivitas ditepi sungai seperti mencari makan, bermain, istirahat dan mencari pohon untuk tidur. Sedangkan saat pagi hari tidak ditemukan bekantan karena air sungai dalam keadaan pasang dan diduga bekantan melakukan aktivitasnya lebih cenderung dibagian dalam hutan mangrove untuk 
menghindari bahaya yang mengancam dari predator.Pada saat dilokasi penelitian di Taman Wisata Alam Tanjung Belimbing telah ditemukan Buaya Muara (Crocodilus porosus) yang diduga menjadi predator dari

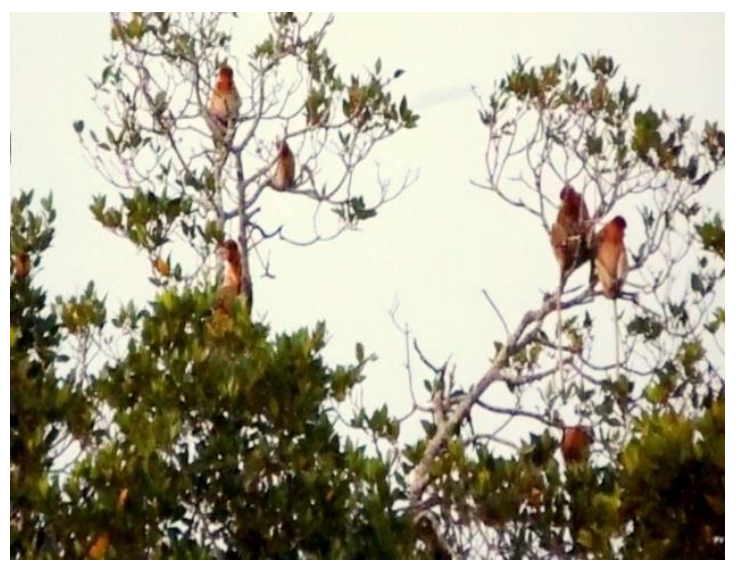

(a)

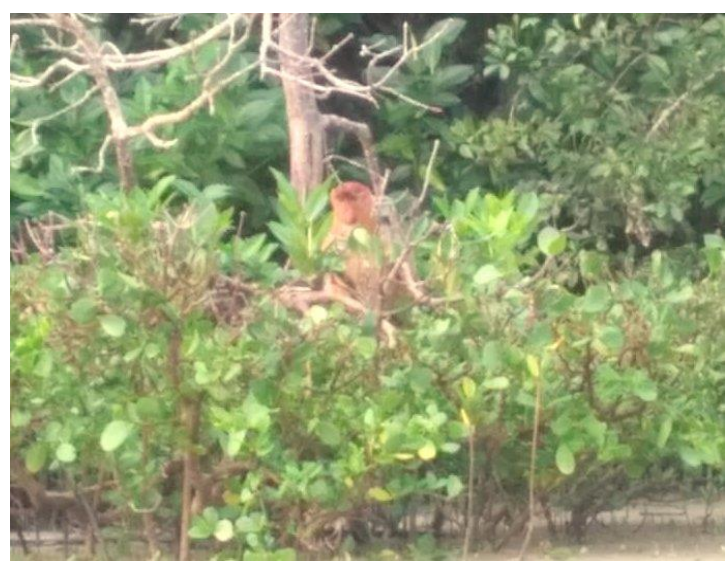

(c) bekantan, buaya muara ini ditemukan dibagian sungai menuju jalur 4-9 yang lebar sungainya sekitar 10 meter. Menurut Atmoko et al., (2007) predator yang memangsa bekantan yaitu Buaya Muara (Crocodilus porosus).

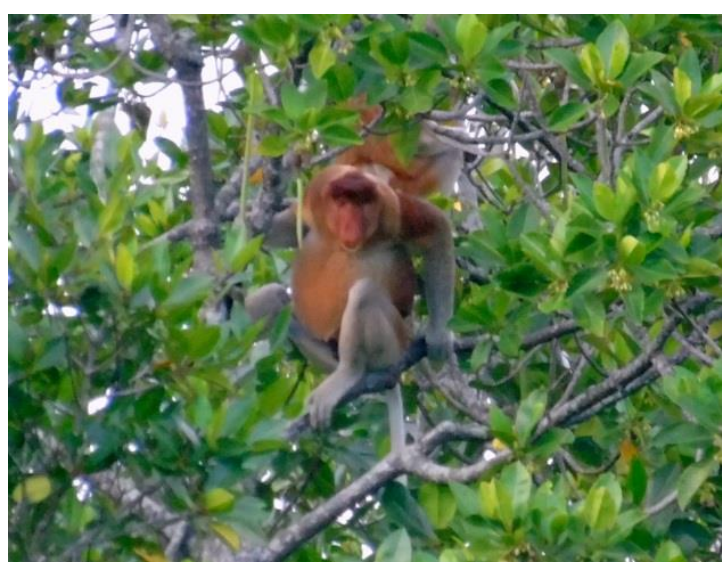

(b)

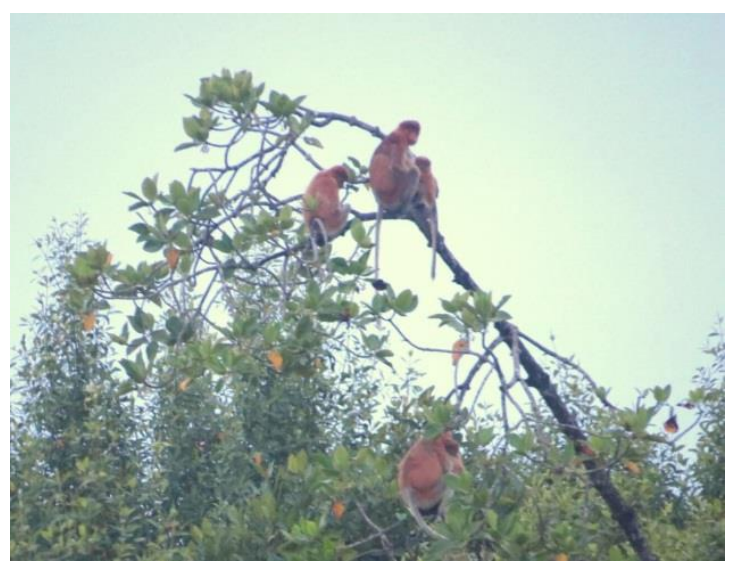

(d)

Gambar 2. Bekantan di Taman Wisata Alam Tanjung Belimbing (Proboscis monkey in Taman Wisata Alam Tanjung Belimbing).

Keterangan : (a). Sekelompok Besar Bekantan Sedang Melakuan Aktivitasnya.

(b). Bekantan Jantan dan Betina Sedang Istirahat.

(c). Bekantan Jantan Sedang Memakan Pucuk Rhizophora sp.

(d). Kelompok Bekantan Sedang Istirahat dan Mencari Makan.

Dari 9 jalur pengamatan bekantan hanya ditemukan pada jalur 1 dan 2 karena pada jalur ini terdapat sumber pakan yang cukup seperti pucuk rambai laut (Sonneratia caesolaris) dan daun dan pucuk bakau (Rhizophora sp.) dan dilokasi pengamatan diberbagai tempat bekantan juga memakan jenis rambai 
laut (Sonneratia caesolaris) (Zainudin \& Amalia, 2016) dan Bruguiera, Rhizophora dan Sonneratia (Suwarto et al., 2016). Sedangkan pada jalur 3 sampai 9 tidak ditemukan. Menurut informasi masyarakat setempat sampai saat ini pada jalur 3 sampai 9 memang tidak pernah terlihat keberadaan bekantan diduga karena sumber pakan yang disenangi yaitu bakau tidak banyak tersedia dan masih berukuran kecil dan pada jalur tersebut banyak di tumbuhi Api-api (Avicennia officinalis) dan Nipah (Nypa fruticans). Pada tegakan hutan yang hanya terdiri dari Sonneratia caseolaris dan Nypa fruticans cenderung mendapat tekanan yang cukup tinggi karena bekantan selalu memakan pucuk dan daun-daun muda Sonneratia caseolaris, lalu pohon nipah (Nypa fruticans) dan Avicennia sp. lebih banyak digunakan sebagai tempat beraktivitas (Atmoko et al., 2007).

Selain faktor kesediaan pohon pakan faktor lain yang diduga sebagai penyebab ketiadaan bekantan pada jalur tersebut adalah adanya aktivitas masyarakat. Jalur 3 sampai 9 merupakan jalur lalu lintas nelayan menggunakan kelotok dan adanya aktivitas warga yang berkebun kelapa di dalam kawasan. Suara kelotok yang nyaring diduga menjadi salah satu faktor bekantan tidak terlihat disepanjang jalur ini, dan diduga juga bekantan akan lari ketika melihat manusia dan mendengar suara kelotok yang mendekat ketepi sungai Taman Wisata Alam Tanjung Belimbing. Salah satu kebijakan dalam pengelolaan TWATB adalah memberdayakan peran serta masyarakat disekitar kawasan, sehingga ditemukan adanya aktivitas warga yang berkebun kelapa dan melintasi kawasan sungai dengan menggunakan kelotok. Hal ini yang diduga menyebabkan keberadaan bekantan tidak ditemukan di jalur 3 sampai 9. Kemudian menurut Suwarto et al., (2016) keberadaan bekantan memang dipengaruhi oleh faktor gangguan seperti akses jalan, pemukiman, dan tambak karena primata ini sangat sensitif terhadap suara dan keberadaan manusia.

\section{Pendugaan Populasi Bekantan}

Pengamatan bekantan dilakukan pada 9 jalur dengan luasan $0,45 \mathrm{~km}^{2}$. Jumlah individu bekantan yang teramati di TWATB sebanyak 23 individu. Pada jalur 1 ditemukan 22 individu dan jalur 2 ditemukan 1 individu dari 3 kali pengamatan. 


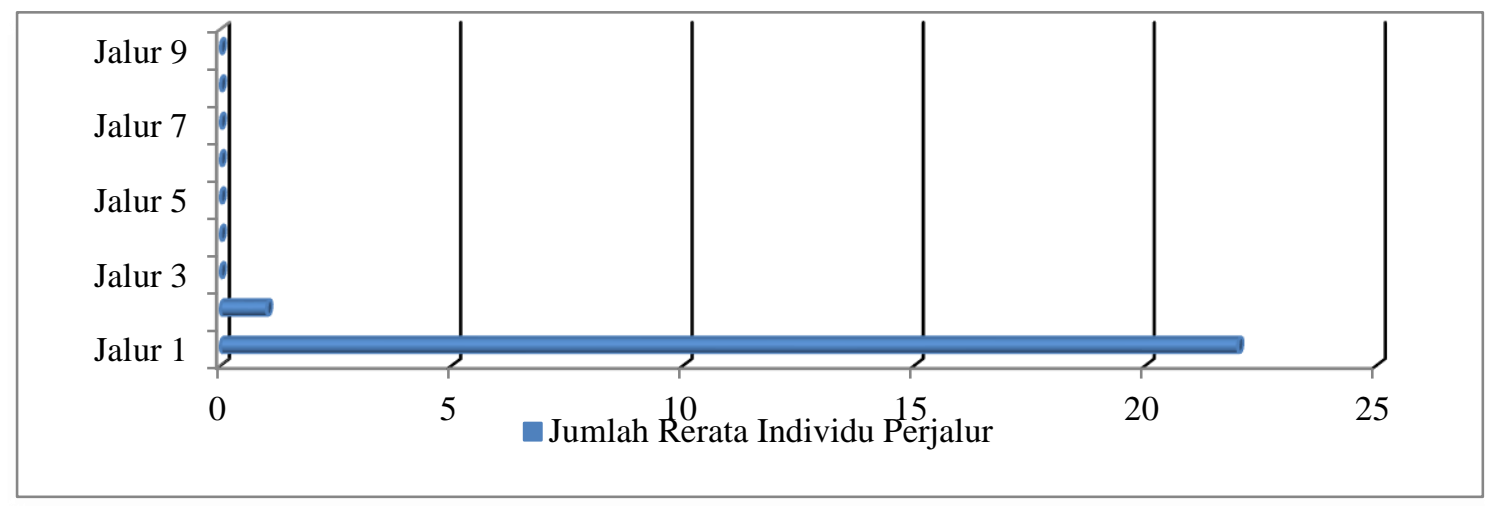

Gambar 3. Rata-Rata Individu Bekantan Perjalur di Taman Wisata Alam Tanjung Belimbing (Average Individual Proboscis Monkey in Taman Wisata Alam Tanjung Belimbing).

Hasil perhitungan pendugaan populasi didapatkan 12 individu dengan kepadatan 25,5 individu $/ \mathrm{km}^{2}$. Populasi bekantan di TWATB memiliki jumlah individu lebih sedikit dibandingdengan jumlah bekantan dibeberapa lokasi lainnya yang ada di Kalimantan seperti Danau Sentarum, Taman Nasional Gunung Palung, Taman Cagar Alam Kendawangan, Cagar Alam Sambas Paloh, dan Taman Nasional Tanjung Puting yang terdapat jumlah bekantan diatas seratus individu setiap lokasi. Perkiraan total individu bekantan di Kalimantan adalah 25.000 individu, yang terdapat didalam kawasan konservasi sekitar 5.000 individu (Manangsang etal., 2005).

Berdasarkan tingkat umur, bekantan yang ditemukan terdiri dari rata-rata 5 individu jantan dewasa $(20,8$ $\%), 6$ individu betina dewasa (25\%), 7 individu remaja $(33,3 \%)$ dan 5 anak $(20,8 \%)$.

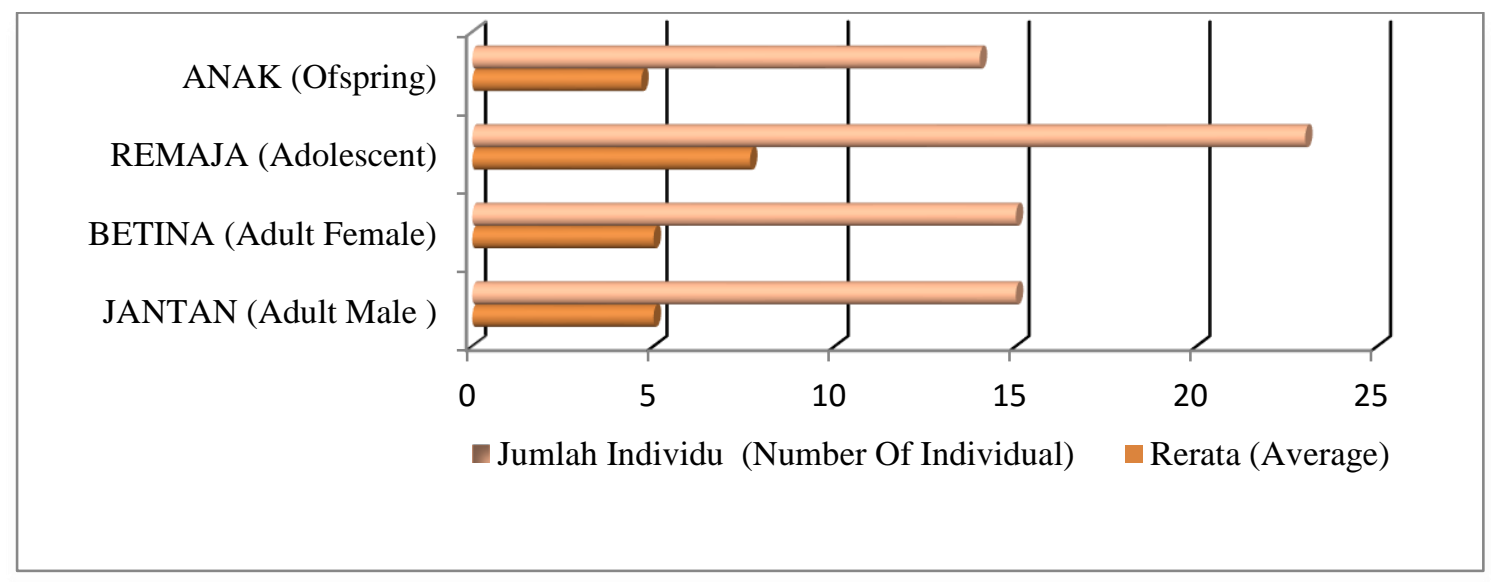

Gambar 4. Bekantan Berdasarkan Tingkat Umur yang Ditemukan di Taman Wisata Alam Tanjung Belimbing (Proboscis Monkey Based on Age Found in Taman Wisata Alam Tanjung Belimbing). 
Bekantan pada tingkat umur remaja lebih banyak ditemukan dibanding jantan dan betina dewasa. Hal ini mengindikasikan adanya pertumbuhan populasi yang baik. Menurut Zainudin \& Amalia (2016) jika individu dengan umur tua memiliki jumlah yang lebih besar dari remaja dan anak, meskipun menunjukkan adanya pertambahan individu dalam kelompok pada setiap tahunnya, populasi bekantan masih digolongkan kedalam kategori populasi menurun. Hal ini sejalan dengan penelitian Iskandar et al., (2017) dimana terdapat individu bayi yang berjumlah 21 individu $(21,43 \%)$ dari jumlah total individu yang dijumpai, hal tersebut memberi petunjuk adanya perkembangan populasi yang meningkat. Strategi Rencana Aksi dan Konservasi Bekantan tahun 2013-2022 yang disusun bertujuan untuk meningkatkan populasi bekantan sejumlah 2,2 \% pertahun melalui perencanaan prioritas kegiatan konservasi insitu dan merancang program pembangunan yang tidak mengancam keberlanjutan populasi bekantan, sehingga kondisi populasi bekantan di alam menjadi lebih baik dalam sepuluh tahun yang akan datang.

\section{Kesimpulan}

Kawasan Taman Wisata Alam Tanjung Belimbing ditemukan 23 individu bekantan yang terdiri dari 5 individu jantan dewasa (20,8\%), 6 individu betina dewasa (25\%), 7 individu remaja $(33,3 \%)$ dan 5 anak $(20,8 \%)$. Hasil perhitungan diduga populasi bekantan terdapat 12 individu dengan kepadatan 25,5 individu $/ \mathrm{km}^{2}$.

\section{DAFTAR PUSTAKA}

Atmoko T, Ma'aruf A, Syahbani, Rengku.2007. Kondisi Habitat dan Penyebaran Bekantan (Nasalis Larvatus, Wurmb) di Delta Mahakam, Kalimantan Timur. Prosiding Seminar Pemanfaatan HHBK dan Konservasi Biodiversitas Menuju Hutan Lestari. Pusat Litbang Hutan dan Konservasi Alam. Hal. $35-42$.

BismarkM dan Iskandar S. 2002. Kajian Total Populasi dan Sruktur Sosial Bekantan (Nasalis larvatus, Wurmb) di Taman Nasional Kutai, Kalimantan Timur. BulPen Hut. No. 631: p.17-29.

Bismark M. 2009. Biologi Konservasi Bekantan (Nasalis larvatus). Siran SA, Setyawati T, editor. Bogor (ID): Pusat Penelitian dan Pengembangan Hutan dan Konservasi Alam.

BKSDA Kal-Bar. 2014. http://skw3bksdakalbar.blogspot.c om/2014/06/taman-wisata-alamtanjung-belimbing.html? $m=1$

IUCN (International Union for the Conservation of Nature and Nature Resources). 2019. www.iucnredlist.org. Diakses juli 2019.

Iskandar S, Alikodra H.S, Bismark M, dan Kartono A.P. 2017. Status Populasi dan Konservasi Bekantan (Nasalis larvatus, Wurmb 1787) di Habitat Rawa Gelam Kalimantan Selatan. Penelitian Hutan dan Konservasi Alam. Vol 14 (2) : 123-132. 
Kartono, A.P, Ginting A, dan Santoso N. 2008. Karakteristik Habitat dan Wilayah Jelajah Bekantan di Hutan Mangrove Desa Nipah Panjang Kecamatan Batu Ampar Kabupaten Kubu Raya Provinsi Kalimantan Barat. Jurnal Media Konservasi. Vol. 13 (3) : 1-6.

Manangsang J, Traylor-Holzer K, Reed D, Leus K (Editors). 2005. Indonesian Proboscis Monkey Population And Habitat Viability Assessment: Final Report. IUCN/SSC Conservation Breeding Specialist Group, Apple Valley, MN.

Peraturan Menteri Kehutanan Republik Indonesia Nomor: P.56/MenhutIi/2013. Strategi Dan Rencana Aksi Konservasi Bekantan (Nasalis larvatus, Wurmb) Tahun 2013-2022.

Peraturan Menteri Lingkungan Hidup dan Kehutanan Republik Indonesia Nomor P.106/Menlhk/Setjen/Kum.1/12/2 018.Tentang Perubahan Kedua Atas Peraturan Menteri Lingkungan Hidup dan Kehutanan Nomor P.20/Menlhk/Setjen/Kum.1/6/201

8 Tentang Jenis Tumbuhan dan Satwa Yang dilindingi.

Peraturan Menteri Kehutanan Nomor: P.57/Menhut-Ii/2008 Tentang
Arahan Strategis Konservasi Spesies Nasional 2008 - 2018.

Sha JCM, Bernard $\mathrm{H}$ and Nathan $\mathrm{S}$ 2008. Status and conservation of proboscis monkeys (Nasalis larvatus) in Sabah, East Malaysia. Primate Conservation (23): 107120.

Soendjoto MA, HS Alikodra, M Bismark, H Setijanto. 2005. Vegetasi Tepi-Baruh pada Habitat Bekantan (Nasalis larvatus, Wurmb) di Hutan Karet Kabupaten Tabalong, Kalimantan Selatan. Biodiversitas 6 (1): 4044.

Suwarto, Prasetyo LB, Kartono AP. 2016. Kesesuaian habitat bekantan (Nasalis larvatus Wurmb, 1781) di hutan mangrove Taman Nasional Kutai, Kalimantan Timur. Bonorowo Wetlands 6 (1): 12-25.

Undang - Undang Republik Indonesia.1990. Tentang Konservasi Sumber Daya Alam Hayati dan Ekosistemnya.

Zainudin, Amalia R. 2016. Struktur Populasi Bekantan(Nasalis larvatus) di Pulau Curiak Kabupaten Barito Kuala Kalimantan Selatan. Prosiding Pendidikan Biologi, FKIP. Universitas Ahmad Dahlan. Riau. 